\title{
Doped and Low-Alloyed Gold Bonding Wires
}

\author{
Ch Simons, L Schräpler and G Herklotz \\ W C Heraeus, Materials Technology Division, Technology Centre, \\ Heraeusstrasse $12-14$, D-63450, Hanau, Germany \\ E-mail:Lutz.Schraepler@heraeus.com
}

Received: 1 February 2000

Fine gold wires with diameters down to $15 \mu \mathrm{m}$ are used for bonding semiconductor devices. Increasing miniaturization of electronic circuits calls for smaller wire diameters. This requires the development of gold wires with increased mechanical strength and good bondability to replace thicker wire diameters without detriment to their functionality. The first gold bonding wires were pure gold, and then doped gold wires of high purity were developed because of their stabilized and improved mechanical characteristics. Nowadays and in the near future low alloyed gold wires are increasingly replacing doped gold wires. This paper gives an overview of the mechanical characteristics of doped and low-alloyed gold bonding wires and their bondability.

Bonding wires serve as electrically conducting connections in integrated and highly integrated circuits (ICs), in automobile, power, and hybrid components. Usual diameters range from $500 \mu \mathrm{m}$ down to $15 \mu \mathrm{m}$. Highest demands are made on the reliability and quality of the wires and resulting wire connections. The most important prerequisites are the uniformity and homogeneity of the wire and its mechanical and electrical characteristics. Thus, bonding wire producers are required to achieve the corresponding properties whilst meeting the highest quality demands.

For automobile, power, and hybrid components socalled thick wires are used from $100 \mu \mathrm{m}$ to $500 \mu \mathrm{m}$ diameter. This wire range is usually made of aluminium and aluminium alloys in order to keep metal costs as low as possible.

In ICs and in components where elevated processing temperatures are possible, gold bonding wires find their optimal application. Moreover, the bonding technology used for gold bonding wires (thermosonic ball-wedge bonding) allows a bonding process about twice as fast as the technology used with aluminium alloy wires (ultrasonic wedge-wedge bonding). Due to the increased cost of the metal, gold bonding wires are usually restricted to diameters from $100 \mu \mathrm{m}$ down to $15 \mu \mathrm{m}$, the so-called fine and ultra-fine wire ranges.

Gold wire bonding technology began with larger wire diameters within this range. Increasing miniaturization of electronics made a reduction of wire diameters necessary. While chip sizes are still decreasing, their functionality is increasing and thus the number of electrical connections is also increasing. This in turn leads to smaller connection pads and pitch sizes. In accord with the change in connection geometries, the most commonly employed wire diameters have been decreasing from $\mathrm{ca} 30 \mu \mathrm{m}$ to $25 \mu \mathrm{m}$ in recent years and will now move towards $20 \mu \mathrm{m}$ within the next three years. Simultaneously the technical demands on the bonding wires have stayed constant, eg the absolute loads, stresses, and electric currents which the wires have to withstand.

\section{BONDING PROCESS AND APPROACH TO GOLD BONDING WIRE DEVELOPMENT}

In order to obtain a more thorough understanding of the importance of the wire characteristics, the bonding process itself (thermosonic ball-wedge bonding) must first be briefly considered. Detailed descriptions and schematic drawings are given in, for example, references $1-4$. At the start of the gold bonding process, a gold ball is melted by means of an electrical discharge at the wire tip, ie the so-called electric flame-off. When melting the ball, the neighbouring wire area is influenced by the heat transfer and a heat-affected zone is formed which can determine 
the loop size and this will be discussed below. The ball is then friction-welded to the chip side bond pad by a mechanical and ultrasonic impact and forms a trumpetlike bond, a so-called ball bond. The ball geometry and its hardness/strength determine its deformation during bonding and whether a faultless joint to the chip pad is achieved. Subsequently the wire loop is formed. In this process various movements of the bonding tool are possible, some of which are complex. In order to permit these movements, the wire has to show appropriate strength and plasticity. At the loop end the wire is joined to the carrier side pad. A mechanical and ultrasonic impact leads to a second bond of flattened circular shape, the so-called wedge bond. Finally the wire is torn off at a predetermined weakened point of the wedge bond and the procedure is repeated beginning with melting the gold ball. The bondloop obtained is illustrated in Figure 1 . After completing the bonding process, the chip and wire loops are injection moulded with a polymer. In this process the wire loops are stressed both by the injection of the polymer and by the shrinkage due to subsequent cooling of the polymer.

The requirement of capability to withstand the high stresses described above and, moreover, the continually decreasing pad and pitch sizes which require smaller wire diameters compel the bonding wire producer to optimize his fine-wire drawing technology and to create

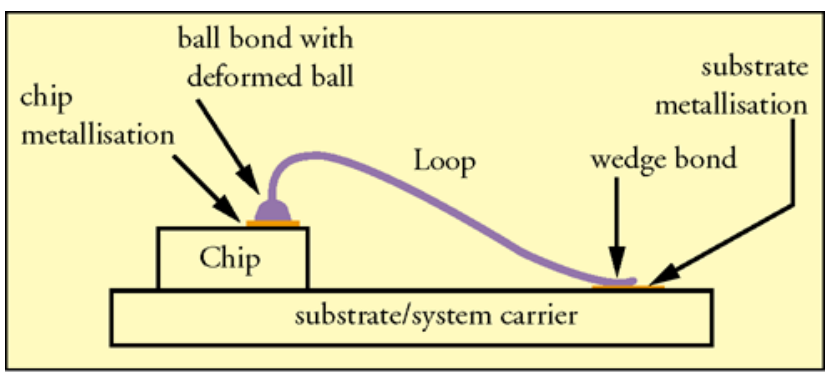

Figure 1 Bond loop

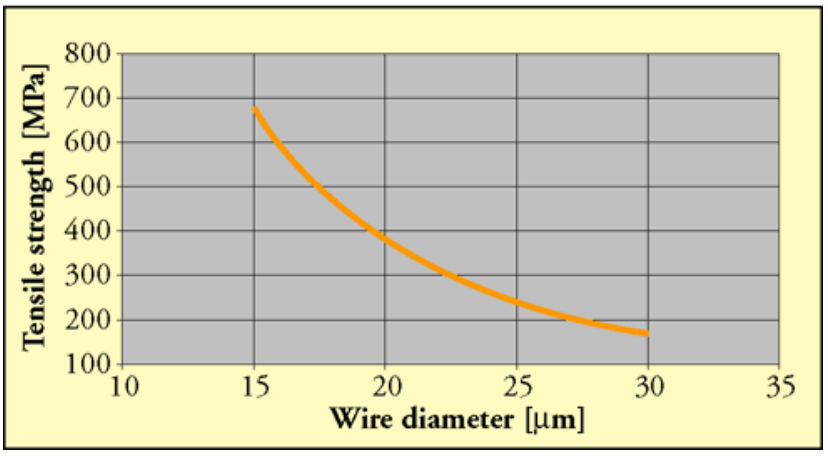

Figure 2 Constant loads at reduced wire diameters demand higher wire strengths new higher-strength wire materials. Wire materials with improved mechanical characteristics allow smaller diameters to be used at constant stresses. Figure 2 gives an example of how this happens in principle. A diameter reduction from $30 \mu \mathrm{m}$ to $20 \mu \mathrm{m}$ requires a wire with more than double the strength in order to withstand constant absolute stresses, as strength, $\sigma$, is proportional to $1 / \mathrm{d}^{2}$, where $\mathrm{d}$ is the wire diameter. In addition, bonding wires with increased mechanical strength permit the more precise and ambitious forming of bonding loops. While keeping wire diameters constant, higher strength wire materials allow very low and long bonding loops with stable loop geometries. Thus, short circuits between two neighbouring wires or between the wire and the system carrier, which might occur due to the so-called sagging or sweeping of the wire within its loop, can be prevented.

\section{COMPOSITION OF GOLD BONDING WIRES}

The most important tool used to tailor mechanical and electrical characteristics of bonding wires has been and still is the chemical composition of the wire material (5). Though optimized microstructures of the same material, created by appropriate drawing and annealing steps, lead to materials with increased strength, the ductility and elongation characteristics simultaneously diminish. This effect leads to problems in forming the loop geometry required and in achieving a faultless bonding joint. Both processes need appropriate plasticity and softness of the wire material.

\section{Low Doped Gold Bonding Wires / High Purity Gold Bonding Wires ${ }^{I}$}

As a result of its softness and adhesive qualities and its inertness in most environments, gold offers many good characteristics for a bonding process. The earliest bonding wires were therefore made of pure gold. 'Pure gold' does not necessarily contain constant impurity levels, however, and it easily recrystallizes during the drawing process. Consequently, the strength obtained is neither constant nor sufficiently high, especially if smaller diameters are required. Thus, at a very early stage, gold materials were developed with defined levels of doping additions. It is necessary to start with high purity gold having $99.999 \%$ purity as the basic material in order to obtain reproducible characteristics and meet the quality required. The main dopants were alkali, alkaline earth and rare earth elements $(1,3,6-9)$. The best known element of this group is

\footnotetext{
${ }^{1}$ Usual description in the Far East
} 
beryllium. Thus, the oldest standard wire material is a beryllium low-doped wire. The dopants are usually in the range up to about $50 \mathrm{ppm}$.

\section{Enhanced Doped Gold Bonding Wires with Higher Strength / Pure Gold Bonding Wires ${ }^{I}$}

In order to meet the need for wires of greater strength, doped wire materials were developed at a later stage by using appropriate combinations of several doping elements up to about $100 \mathrm{ppm}(7,10)$. Dopant elements used were those of the alkali, alkaline earth and rare earth groups as well as elements of Groups 3 and 4 of the Periodic System. Here the composition of doping elements plays an important role. For example, in a number of patents the following elements are recommended: $\mathrm{K}, \mathrm{Be}, \mathrm{Mg}, \mathrm{Ca}, \mathrm{Ba}, \mathrm{La}, \mathrm{Ce}, \mathrm{Zr}$, Ga, In, $\mathrm{Ge}, \mathrm{Pb}, \mathrm{Cu}, \mathrm{Ag}, \mathrm{Pt}, \mathrm{Pd}, \mathrm{B}(1,7,11-13)$. Exact data are usually not available as these belong to the proprietary knowledge of the bonding wire producers. Also, exact analytical data are difficult to obtain as the individual dopant element may be present at levels of under 10 ppm. Reliable comparative measurements in this range are difficult to obtain due to lack of reliable calibration standards and the presence of small additional impurities arising from the melting and casting processes. These more highly doped gold materials are used for more difficult loop geometries and offer better strengths and a higher thermal stability. A major part of current bonding wire consumption is covered by enhanced doped / pure gold wires.

\section{Low Alloyed Gold Bonding Wires with Highest Strength}

The latest developments have brought low-alloyed gold bonding wires on to the market. These gold alloys usually contain up to $1 \%$ alloying elements, in some cases up to $5 \%(14,15)$. The most important alloying elements are the precious metals $\mathrm{Ag}, \mathrm{Pd}, \mathrm{Pt}$, and also $\mathrm{Cu}(10,16-18)$. Other elements are also used, but preferably at lower concentrations to minimize the danger of corrosion (19). The alloying elements are accompanied by doping elements from the groups mentioned above. These wires are now starting to be used in Europe and already have a market share of about $30 \%$ in Asia. The advantages of these wires are obvious: the great increase in strength enables much better workability even with difficult bonding geometries. With an additional increase in high temperature strength they reveal a higher thermal stability and thus a wider field of application. These wires are especially suitable for new bonding techniques using higher speed, higher frequency and lower temperature, and also for low and long loops, and for fine pitch/fine size bonding.

The amount of alloying elements is restricted mainly by the following considerations:

- Alloying elements increase electrical resistivity (see below).

- Some alloying elements lead to non-conforming ball geometries and to oxidation problems during the ball melting of the bonding process and decrease the corrosion stability in the long term application. These are in particular nonprecious metals such as $\mathrm{Ti}, \mathrm{Zr}, \mathrm{Fe}, \mathrm{Ni}, \mathrm{Co}$, etc.

- More highly strengthened materials usually show a higher hardness which might become a problem during the bonding process because good ball deformation and an appropriate soft ball are necessary to create a stable bond joint without damaging the substrate material.

Thus, in general, the use of higher alloyed gold bonding wire materials is severely restricted.

\section{WIRE CHARACTERISTICS}

\section{Wire Material Strengthening}

Figure 3 permits a direct comparison of the various doped and alloyed classes of gold bonding wires. The strengthelongation curves represent various microstructural states generated by a cold working process and an annealing treatment. The high strength / low elongation ratio relates to the hard drawn wire state, and the low strength / high elongation ratio describes the recrystallized condition. Typically the curves follow the slopes shown, as an increase in elongation results in a decrease in strength. Thus, different levels of strength are shown over a wide elongation range which adequately covers all the technical requirements of a successful bonding process. In order to simplify the comparison the $4 \%$ elongation point is quite

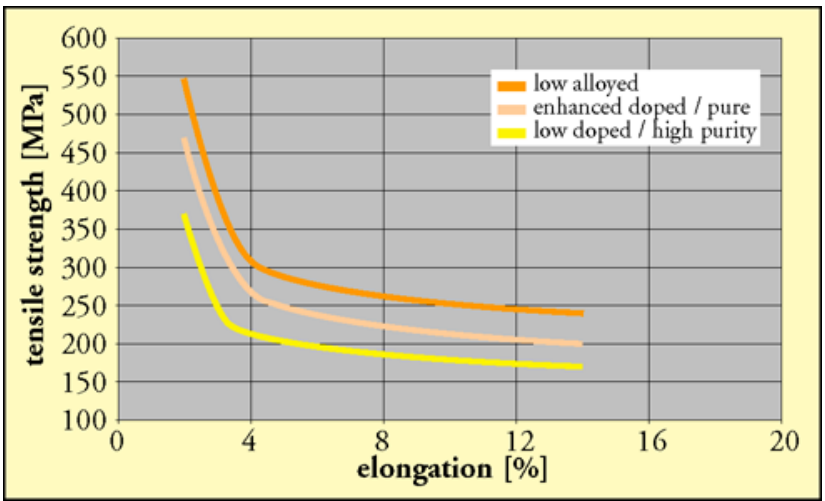

Figure 3 Strength-elongation diagram of gold bonding wires 
useful as it represents a wire condition that is often requested.

Doping of pure gold material is assumed mainly to stabilize its grain boundaries. Thus, a stabilization of strength characteristics is obtained even with low doping concentrations. This effect is enhanced by using appropriate concentrations and combinations of doping elements. As the characteristic doping elements (alkali, alkaline earth and rare earth elements) have very low or even zero solubility in gold $(20,34)$ in the solid state, they should precipitate out as intermetallic compounds on the grain boundaries during solidification, thus stabilizing and pinning the grain boundaries and hindering dislocation movement in subsequent deformation processes. The work hardening effect and the recrystallization temperature are increased leading to increased strength. During annealing, grain growth is restricted by the large number of grain nuclei and by pinning or hindering the movement of grain boundaries resulting in a finer grain structure with stabilized grain boundaries. Thus the higher strength is also effective in the recrystallized state. However, exact metallurgical investigations of the effect and location of doping elements in gold have not been carried out and this field deserves further intensive work $(2,3,5,21,34)$.

With an enhanced doped / pure gold wire material the improvement in tensile strength is about $20 \%$ at the same elongation levels compared with low doped / high purity gold materials. So a tensile strength of ca $260 \mathrm{MPa}$ is achieved at 4\% elongation whereas low doped / high purity materials reach $c a 210 \mathrm{MPa}$.

Obviously, the greatest increase in strength is obtained by the low alloyed gold materials. In the cast state, these materials already show much finer grain structures than cast doped materials because the higher impurity levels provide numerous nuclei for grain formation at many locations in the solidifying melt (22). Figure 4 illustrates a comparative example. As the commonly employed alloying elements usually have a significant solubility in the gold, a solid solution strengthening effect is also obtained. Work hardening is therefore increased by solid solution hardening and grain refining effects, leading to much higher strengthening levels and also to increased recrystallization temperatures (22). Precipitation hardening, which gives stronger effects than those of the doping elements discussed above, can be obtained, for example by titanium $(23,24)$. However, this approach is not yet commonly used because it is generated mainly by alloying elements that increase the corrosion risk and often give ball hardnesses which are too high. The strengths of low-alloyed gold materials are around 20\% higher than those of enhanced doped / pure gold, ie an increase from

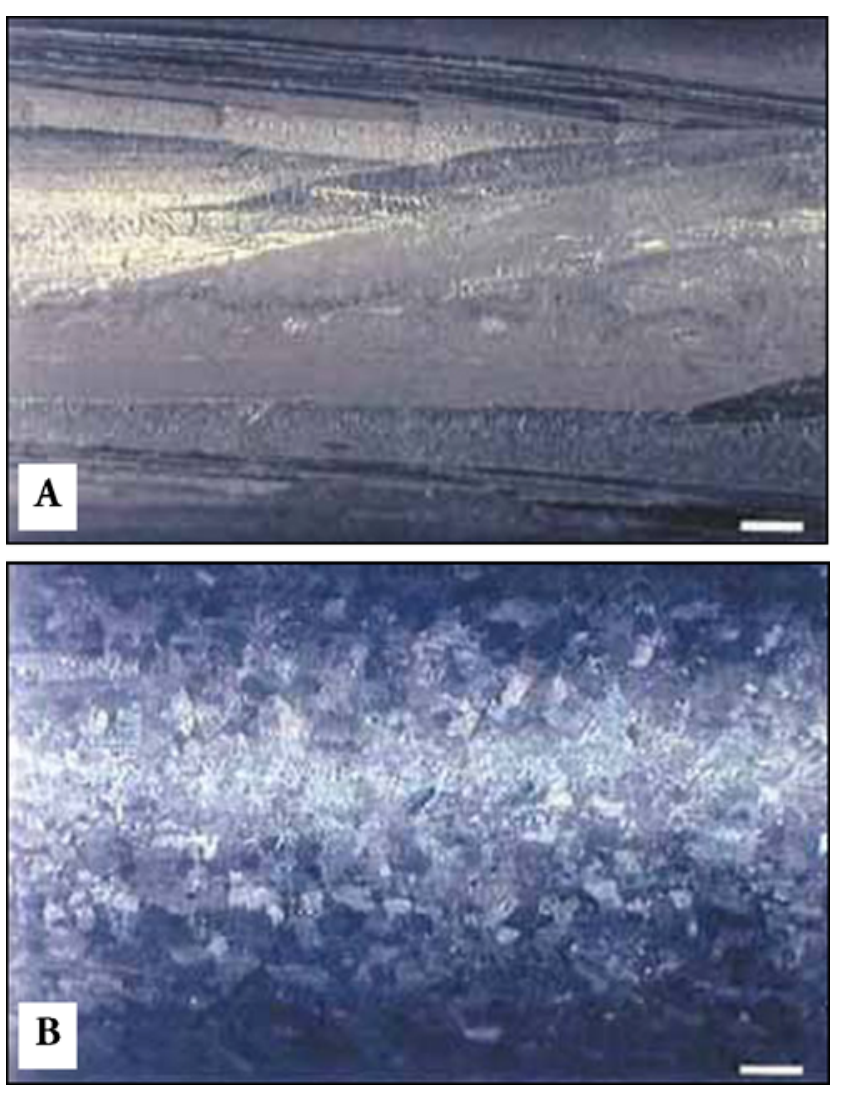

Figure 4 Cast strands of doped gold (Figure $4 A$ ) and low alloyed gold (Figure 4B), scales $1 \mathrm{~mm}$

ca $260 \mathrm{MPa}$ (enhanced doped / pure) to $c a 310 \mathrm{MPa}$ (lowalloyed) at the $4 \%$ elongation level.

\section{High Temperature Strength}

Gold bonding wires usually have to withstand temperature exposures of up to $c a 150^{\circ} \mathrm{C}$, and in recent automotive engine applications up to $200^{\circ} \mathrm{C}$. The bonding process itself is usually carried out with heated substrate materials up to $150^{\circ} \mathrm{C}$, in some cases up to $250^{\circ} \mathrm{C}$, in order to improve the welding of wire and pad material at the bonding point. After bonding a moulding polymer covers the complete system. Moulding polymers reach temperatures of up to $c a 200^{\circ} \mathrm{C}$. Thus, shrinkage occurs during cooling and stresses the wire especially at its weakest locations. In addition, some applications require stability for long term exposure at $200^{\circ} \mathrm{C}$. As the temperature exposure will lead to a decrease in strength, knowledge of the high temperature strength is necessary to enable every user to choose the most suitable wire. The high temperature strength of gold bonding wire materials is therefore compared in Figure 5. By analogy with the effects described in Section 1 above, a considerable increase in high temperature strength is achieved by 


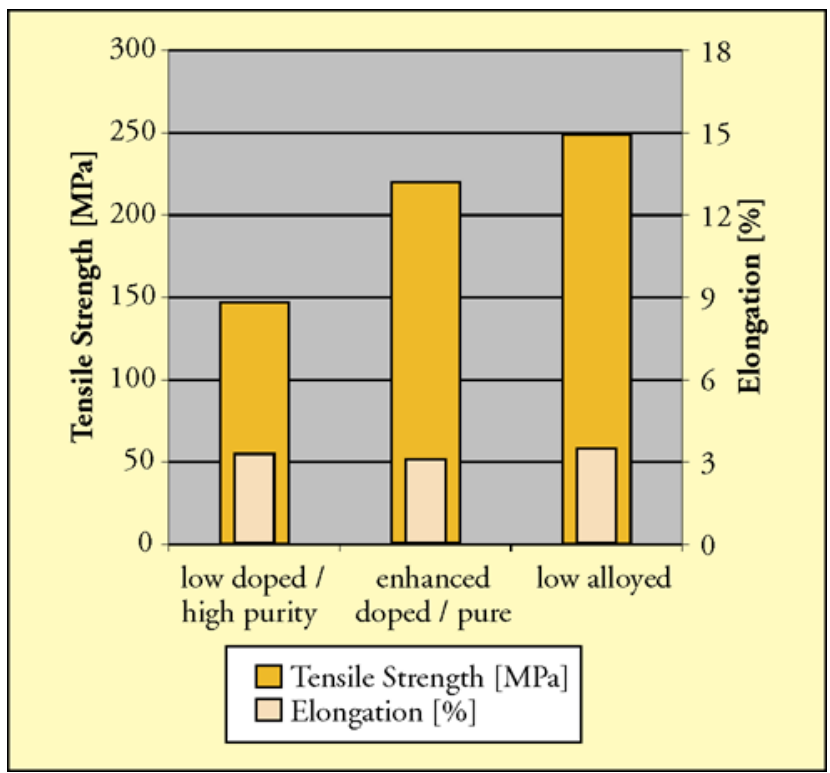

Figure 5 High temperature strength of gold bonding wires after $250^{\circ} \mathrm{C}$ exposure for $20 \mathrm{sec}$

enhanced doped / pure gold wires, but here again the highest strength values are obtained with low-alloyed wire materials. The reasons for this behaviour are directly connected with the enhanced basic strength and the microstructure stabilizing influence of the doping / alloying elements described above.

\section{Heat Affected Zone}

The melting of a gold ball at the beginning of every bonding process influences the adjoining wire area. Thermal conductivity causes a recrystallized length of the wire in the zone near the ball, the so-called heat-affected zone $(5,10)$. This zone is disadvantageous because it has a coarser grain structure and therefore lower strength (Hall-Petch relationship). While bending the wire from the ball bond to the required loop height, critical stresses may occur in the heat affected zone. When forming low loop geometries, the length of this zone is the most critical factor. Figure 6 shows a wire with a melted gold ball at the wire tip and its heat affected zone. In Figure 7 the gold ball is bonded to the substrate pad, but the

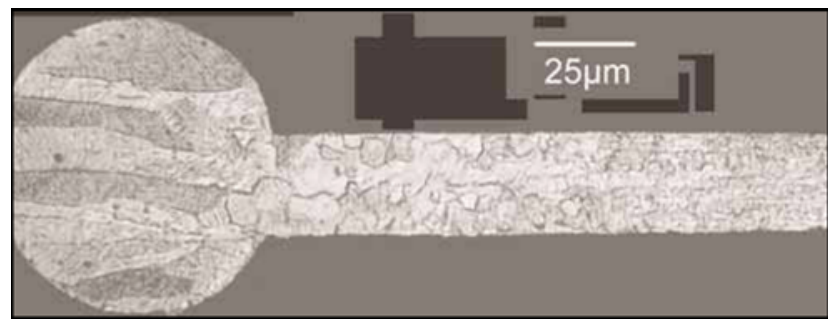

Figure 6 Section through a low alloyed gold bonding wire with melted gold ball and heat affected zone

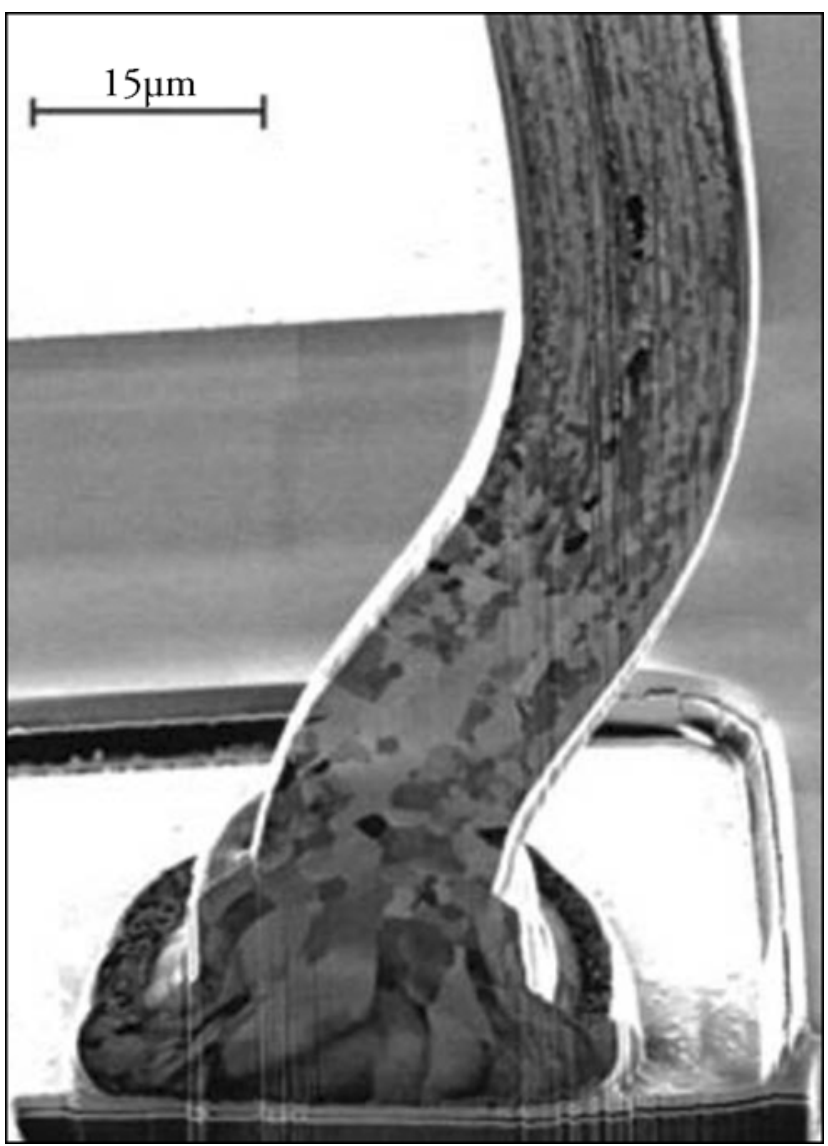

Figure 7 Photograph of a bonded low alloyed gold wire showing ball bond with deformed ball and heat affected zone

neighbouring heat affected zone is only slightly deformed in order not to overstress the wire.

Figure 8 shows a comparison of heat affected zones of the different wire groups. The recrystallization behaviour of the wire material determines the length of this zone. According to the explanations in Section 1 above, the length of this zone is reduced with increasing concentration and appropriate type of doping / alloying elements. Minimum heat affected zones well below $100 \mu \mathrm{m}$ can be obtained by using low-alloyed gold bonding wires. In this way the formation of very low and stable loops is possible.

\section{Resistivity}

As the electrical resistivity increases with the concentration and type of alloying element, control of this property may be crucial for some applications. Doping in the range described here leads to negligible increases in resistivity. Low-alloyed wires have resistivities ca 50\% higher than doped gold. Figure 9 gives the resistivities of the gold wire materials. For alloying ranges up to $5 \%$ the increase in resistivity can be estimated using the Matthiesen rule. 


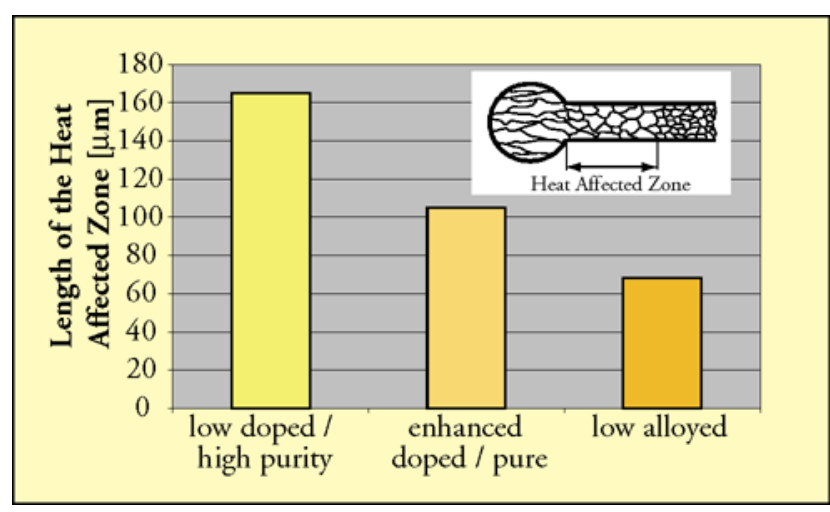

Figure 8 Heat affected zones of gold bonding wires (wire diameter $25 \mathrm{~mm}$, ball diameter $40 \mathrm{um}$ )

\section{BONDABILITY AND RELIABILITY}

The bondability of a wire is mainly described by the melting of a gold ball, the deformation process of the ball during bonding, and the formation of a stable bond joint. In addition to the influence of the bonding equipment, ball melting and deformation are determined by the wire, whereas the bond joint is determined by both wire and pad. The pad surface and layer characteristics play an important role, ie cleanliness and roughness of the pad

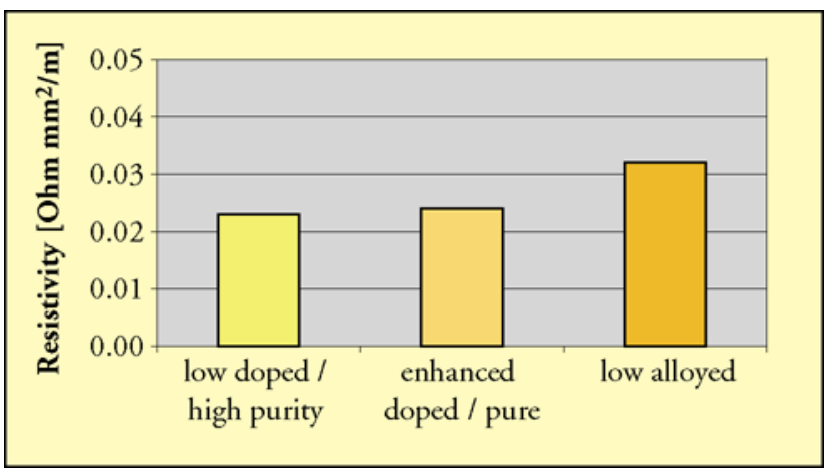

Figure 9 Electrical resistivity of gold bonding wires

surface, appropriate geometries and construction of the layers and their chemical composition and physical condition. The melting of a gold ball has to create a ball of good conformity, $i e$ the ratio between ball width and ball height, and high reproducibility. Although doping and alloying elements can affect the ball geometry disadvantageously (5), the exact spherical shape may be less important as good bonding can also be achieved with non-spherical balls. The main factors determining high reproducibility and appropriate geometry are the melting time and electric current during the electric flame off. Typical values for a d $=25 \mu \mathrm{m}$ wire with a ball size of $1.4 \mathrm{~d}$ $-2.4 \mathrm{~d}$ might be $1.5-2 \mathrm{~ms}$ and $20-25 \mathrm{~mA}$, depending on the equipment. Using defined variation of these parameters, a process window for the most suitable parameters can be achieved for every wire type on every bonding machine.

The resulting ball hardness is a function both of these parameters and of the wire material. The hardness and strength of the ball are determined by its chemical composition and the microstructure. Thus the doping and alloying elements and the ball melting process determine hardness and strength. High strength wire materials result in slightly higher strength and hardness of the wire balls under comparable melting parameters as can be seen from Table 1. Higher hardnesses than those of the low-alloyed gold wire balls are limited by the danger of chip cratering, ie the impact of a ball that is too hard may damage the chip.

After melting the ball, the subsequent bonding process begins by pressing the ball onto the chip pad. Here the ball is deformed under the parameters of static bonding force and ultrasonic power impact. A typical deformed ball after ball bonding is illustrated in Figure 7. The ball deformation is given as the diameter of the bonded ball in the bonding plane. By varying the parameters of bonding force and ultrasonic impact a process window for a defined ball deformation ratio (ie bonded ball diameter: melted ball diameter) can be achieved for different wire types as shown in Figure 10. Low-alloyed wires show less sensitivity to variations in these parameters and therefore allow a wider process window for the bonding machine than doped wires. Low doped / high purity and enhanced doped / pure wires do not differ very much and are typified by the curves in Figure 10A).

The bond joint generated has to reveal a pore-free material junction between wire and pad in order to give faultless function. Nevertheless, during extended working at higher temperatures diffusion processes occur between the gold of the wire and the aluminium of the pad, leading to the formation of various $\mathrm{Au}_{\mathrm{x}} \mathrm{Al}_{\mathrm{y}}$ intermetallic phases in the interface area combined with the generation of Kirkendall voids mainly at the interface between the intermetallic phases $(1,25-29)$. Both intermetallic phases and Kirkendall voids influence the strength of the bonding joint and determine the long-term reliability of the electronic component. Whereas the intermetallic phases may lead to a strengthening effect in the bond joint, the Kirkendall voids may increase to the size of

Table 1 Average Ball Hardness of Different Types of Gold Wire

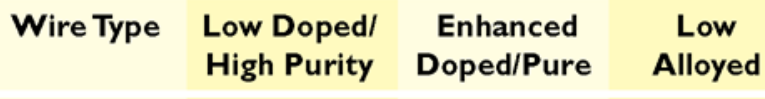

$\begin{array}{llll}\text { Hardness Hv } & 55 & 60 & 65\end{array}$ 

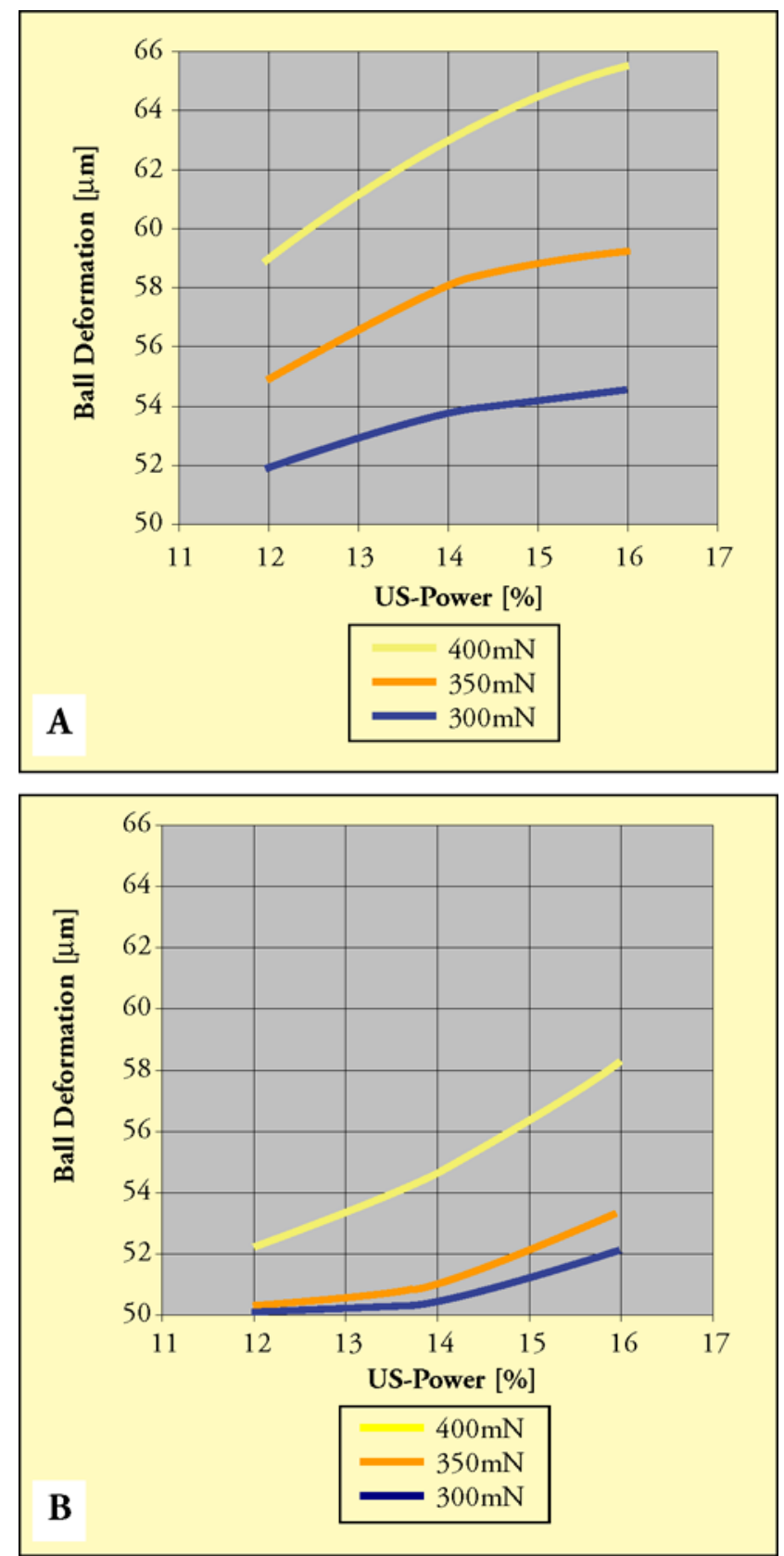

Figure 10 Ball deformation of gold bonding wires vs bonding parameters ultrasonic power and bond force (wire diameter $25 \mathrm{um}$, ball diameter $40 \mathrm{um}$ ); for doped gold bonding wire (Figure 10A) and low alloyed gold bonding wire (Figure 1OB)

pores and link up leading to a separation between phase interfaces, thus weakening or even destroying the bond joint. Figure 11 demonstrates the generation of an intermetallic phase mainly growing into the wire side of the bond after temperature exposure of $150^{\circ} \mathrm{C}$ for $500 \mathrm{~h}$. As the phase growth is mainly observed in the direction of the wire side, gold-rich compositions of the $\mathrm{Au}_{\mathrm{x}} \mathrm{Al}_{\mathrm{y}}$ phases

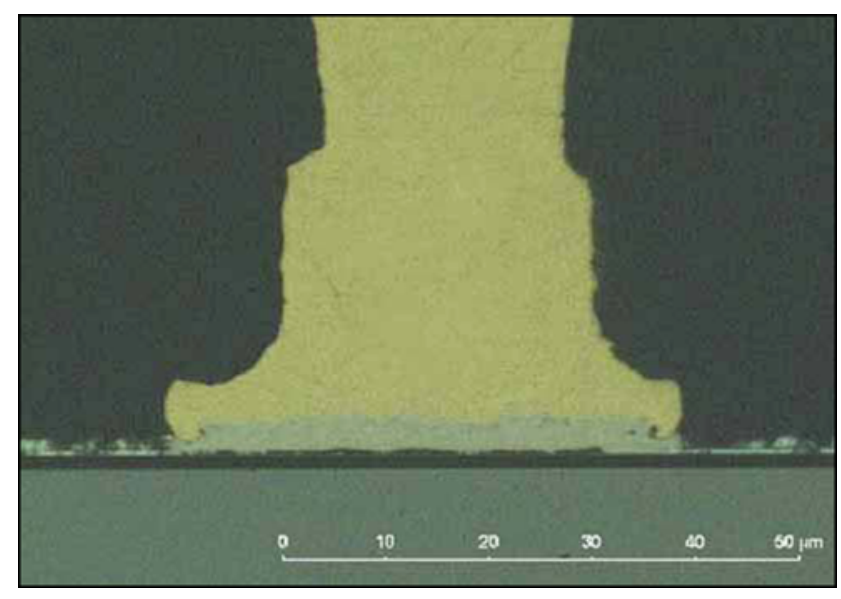

Figure 11 Section through a temperature exposed $\left(150^{\circ} \mathrm{C}, 500 \mathrm{~b}\right)$ low alloyed gold ball bond

such as $\mathrm{Au}_{4} \mathrm{Al}$ are dominant. Our own results with longterm temperature exposures show slight advantages of a reduced intermetallic phase thickness for bonds with lowalloyed wires (Table 2). Accordingly, the size and quantity of Kirkendall voids should be reduced for the low alloyed wire bond. The first Kirkendall voids in visible pore sizes have been detected for exposures at $150^{\circ} \mathrm{C}$ and $1000 \mathrm{~h}$ for a doped wire bond, whereas a low alloyed wire bond shows visible pores only after more challenging exposures at $200^{\circ} \mathrm{C}$ and $500 \mathrm{~h}$.

Reliability tests prove the bond joints and wire strength in the bonded condition under exposure to different relevant parameters such as temperature and humidity (30). An important test for the ball bond joint is the shear test in which a tool moves parallel to the chip surface contacting the ball bond and shearing it off. For the pull test a hook is located under the bond loop and pulls the loop until it tears. Different hook positions relative to the loop can evaluate different wire/loop zones.

Reliability tests after long-term temperature exposure indicate higher shear strength values for the low alloyed wires, as illustrated in Figure 12A. Figure 12B shows that the pull strength of low-alloyed wires also lies slightly above that of doped wires. Wedge bond testing by the pull test also shows slightly better values for the alloyed wires (Figure 12C). Low-doped / high purity and

Table 2 Thickness of Intermatallic Phase of Temperature Exposed $\left(150^{\circ} \mathrm{C}, 500 \mathrm{~h}\right.$, Gold Ball Bonds

\section{Wire Type Low Doped/ Enhanced Low High Purity Doped/Pure Alloyed}

Intermatallic

Phase Thickness $\quad 3.8 \mu \mathrm{m} \quad 3.4 \mu \mathrm{m} \quad 3.1 \mu \mathrm{m}$ 

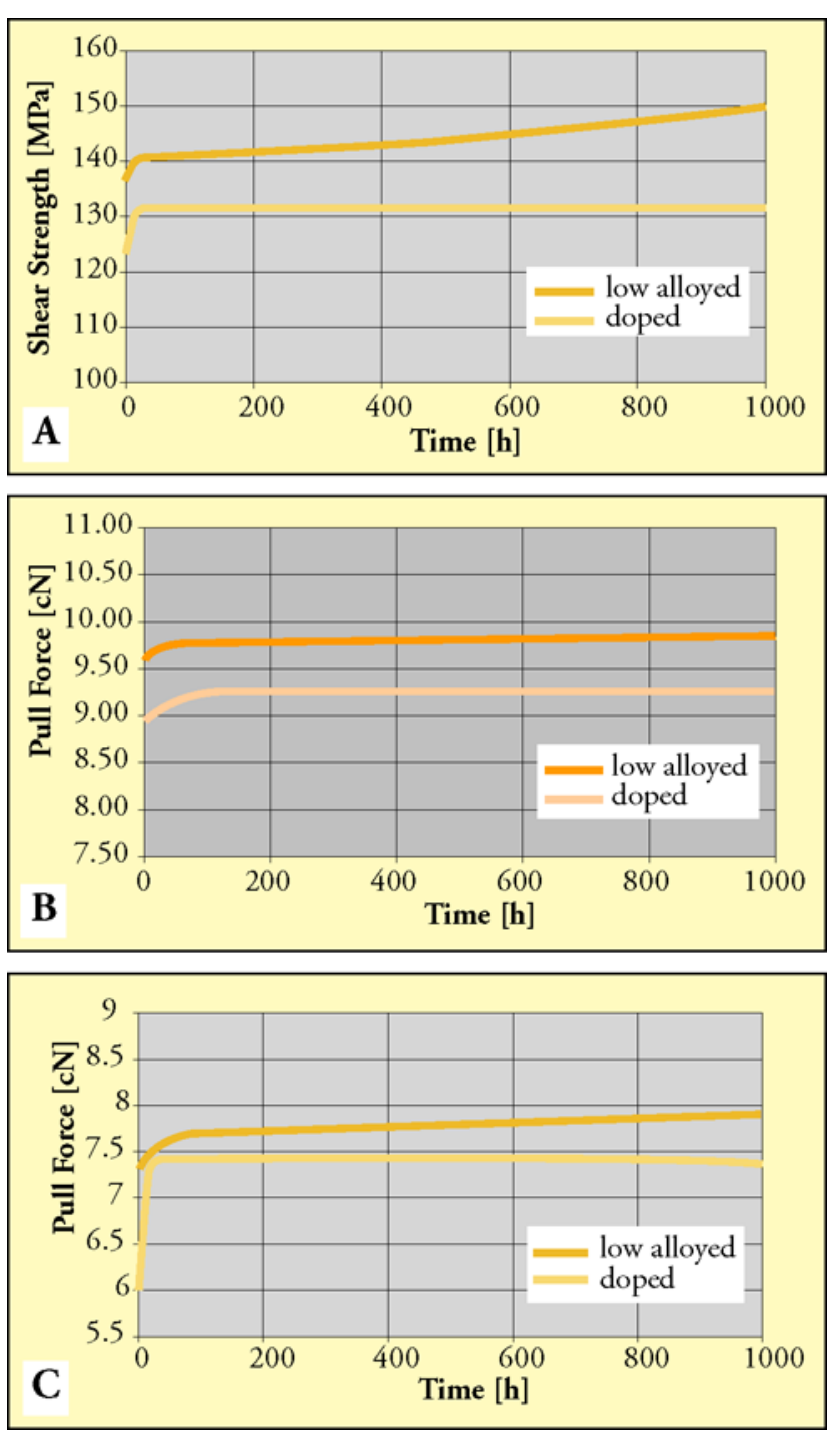

Figure 12 Reliability tests of $25 \mu \mathrm{m}$ gold wire bonds after temperature exposure at $150^{\circ} \mathrm{C}$ : shear test (Figure 12A); pull test, hook near ball bond (Figure 12B); and pull test, hook near wedge bond (Figure 12C)

enhanced-doped / pure gold wires are shown in one curve due to the negligible differences in reliability values.

It is remarkable that no test reveals a degradation of the bonds. Instead the pull and shear forces obtained increase slightly at the beginning of the temperature exposure because of the strengthening due to interdiffusion in adjoining areas in the contact zone between wire and pad and also due to the formation of intermetallic phases. Whereas pull forces remain fairly constant over long-term temperature exposure, the shear strength increases distinctly with exposure time for the low alloyed wire bonds.

\section{SUMMARY AND FUTURE OUTLOOK}

The characteristics of doped and low-alloyed gold bonding wires have been elucidated as well as their bondability and reliability. Whereas low doped / high purity gold bonding wires were mainly used in the past, enhanced doped / pure gold bonding wires have now become the standard bonding wire material. They will be replaced now and in the near future by low-alloyed gold wires as these materials show many advantages compared with the standard doped wire materials. A general improvement in wire strength is accompanied by an improvement in bondability and reliability of the bonding joint.

Nevertheless, much work is still needed to develop further optimized wire alloys. The most restricting obstacles are the requirement of electrical resistivity very close to that of gold itself, the condition of the pad-side layers which demand fairly soft gold alloys in order to withstand the bonding process without any cratering defects, and the necessary resistance to corrosion by contact with gaseous and solid environments. These demands permit only a few and very low concentrations of alloying elements. Thus the development of more highly alloyed gold wires has not yet really started to accelerate. The focus will be on the low alloyed gold wire materials in order to match the different demands with the most suitable wire. Furthermore, highly doped wire materials with enhanced strength might be optimized in order to combine the qualities of doped / pure and low-alloyed wires.

Of special interest may be particle / metal reinforced wires (31 - 33) which reveal interesting materials characteristics. However, the bondability of these wires still has to be established.

\section{ABOUT THE AUTHORS}

Dr Christoph Simons was a development project manager in the Technology Centre at WC Heraeus in Hanau until January 2000 . He was mainly engaged in the development of and production improvement processes for bonding wires. He is now with Leybold Materials in Hanau.

Lutz Schräpler is the worldwide technical coordinator for bonding wires at W C Heraeus, responsible for development and production technology at all the Heraeus wire production sites.

Dr Günther Herklotz was head of development at the Heraeus Technology Centre until June 1999, responsible for electronic and packaging materials, and now acts as a consultant on these topics.

Continued on page 102 


\section{ABOUT THE AUTHOR}

Dr Mark Humphrey completed his PhD with Professor Michael Bruce at the University of Adelaide, Australia, in 1987. He then undertook postdoctoral research with Professor Gerhard Erker at the Universität Würzburg, Germany (1987-1989) and with Professor John Shapley at the University of Illinois, USA (1989-1990). He was appointed to a Lectureship in Chemistry at the University of New England, Australia, in 1990, moving to the Australian National University in 1994, where he is currently an ARC Australian Senior Research Fellow and Reader in the Department of Chemistry. He is the author of one hundred scientific papers, many dealing with the nonlinear optical properties of organometallic complexes.

\section{REFERENCES}

1 S.R. Marder, J.E. Sohn and G.D. Stucky (Eds), Materials for Nonlinear Optics: Chemical Perpectives, ACS Symposium Series 455, ACS, Washington DC, 1991

2 H.S. Nalwa and S. Miyata (Eds), Nonlinear Optics of Organic Molecules and Polymers, CRC Press, Boca Raton, Florida, 1997

3 R.L. Sutherland, Handbook of Nonlinear Optics, Marcel Dekker, New York, NY, 1996

4 J. Zyss, Nonlinear Opt., 1991, 1,3

5 S. Houbrechts, T. Wada, H. Sasabe, J.P.L. Morrall, I.R. Whittall, A.M. McDonagh,
M.G. Humphrey and A. Persoons, Nonlinear Opt., 1999, 22, 165

6 I.R. Whittall, M.G. Humphrey, A. Persoons and S. Houbrechts, Organometallics, 1996, 15,5738

7 S. Houbrechts, C. Boutton, K. Clays, A. Persoons, I.R. Whittall, R.H. Naulty, M.P. Cifuentes and M.G. Humphrey, J. Nonlinear Opt. Phys. Mater., 1998, 7, 113

8 S. Houbrechts, K. Clays, A. Persoons, V. Cadierno, M.P. Gamasa, J. Gimeno, I.R. Whittall and M.G. Humphrey, SPIE Proc, Int. Soc. Opt. Eng., 1996, 2852, 98

9 A.M. McDonagh, N.T. Lucas, M.P. Cifuentes, M.G. Humphrey, S. Houbrechts and A. Persoons, J. Organomet. 2000. 605, 193

10 R.H. Naulty, M.P. Cifuentes, M.G. Humphrey, S. Houbrechts, C. Boutton, A. Persoons, G.A. Heath, D.C.R. Hockless, B. Luther-Davies and M. Samoc, J. Chem. Soc., Dalton Trans, 1997, 4167

11 I.R. Whittall, M.G. Humphrey, S. Houbrechts, J. Maes, A. Persoons, S. Schmid and D.C.R. Hockless, J. Organomet Chem, 1997, 544, 277

12 I.R. Whittall, M.G. Humphrey, M. Samoc, B. Luther-Davies and D.C.R. Hockless, J. Organomet. Chem., 1997, 544, 189

13 I.R. Whittall, M.G. Humphrey, M. Samoc and B. Luther-Davies, Angewu. Chem., Int. Ed. Engh, 1997, 36, 370

14 J. Vicente, M.T. Chicote, M.D. Abrisqueta, P.G. Jones, M.G. Humphrey, M.P. Cifuentes, M. Samoc and B. Luther-Davies, Organometallics, 2000, 19, 2968

15 J. Vicente, M.-T. Chicote, P. González-Herrero, P.G. Jones, M.G. Humphrey, M.P. Cifuentes, M. Samoc and B. Luther-Davies, Inorg. Chem, 1999, 38, 5018

16 H. Zheng, W. Ji, M.L.K. Low, G. Sakane, T. Shibahara and X. Xin, J. Chem, Soc,, Dalton Trans, 1997, 2357

17 T. Kamata, T. Kawasaki, T. Kodzasa, H. Ushijima, H. Matsuda, F. Mizukami, Y. Nakao, Y. Fujii and Y. Usui, Synth. Met., 1999, 102, 1560
Continued from page 96

\section{REFERENCES}

1 AVT Report 4, Technologie des Drahtbondens, Germany, August 1991

2 'High Technology Bonding Tools', Gaiser Tool Company, Ventura, California, 1989

3 W. Kohl, The Interaction of Material and Machine Parameters in Thermosonic Bonding',translation of a reprint from 'Der Elekuroniker' Issue 6/1990, AT-Fachverlag, Stuttgart, Germany, 1991

4 Merkblatt DVS 2810 Drahtbonden, (instructional leaflet, wire bonding), Germany, 1992

5 S. Tomiyama and Y. Fukni, Gold Bull., 1982, 15 (2), 43

6 W. Kohl, 'Metallurgical Aspects of Wire Bonding', printed by Heraeus, 1990 ASTM-F72

Japanese Patent Application 5-179375 A

Japanese Patent Application 5-179376 A

10 T.H. Ramsey, Solid State Technology, 1973, Oct, 43-47

German Patent Application DE 3936281 A1

European Patent Application 0743679 A2

German Patent 1608161

US Patent 5491034

Japanese Patent 6-112251

European Patent 0288776

German Patent Application DE 19733954 A1

European Patent Application 0761831 A1

9 Japanese Patent Application 52-051867 A
20 T.B. Massalski, 'Binary Alloy Phase Diagrams', 2nd Ed., ASM International, Ohio, USA, 1990

21 Merkblatt DVS 2807 Teil 1, Zusatzwerkstoffe für Mikroverbindungen, Bonddrähte und Bändchen, (instructional leaflet, Addicion Materials for Microjoints, Bonding Wires and Ribbons), Germany, 1992

22 D. Ott and Ch. J. Raub, Gold Bull., 1981, 14 (2), 69

23 D.M. Jacobson, M.R Harrison, S.P.S. Sangha, Gold Bull, 1996, 29 (3), 95

24 G. Humpston and D.M. Jacobson, Gold Bull., 1992, 25 (4), 132

25 W. Kohl, S. Weber and A. Bischoff, Metallographic Investigation of the Au-Al Intermetallic Phase Formation, Metallography Conference of Deutsche Gesellschaft für Metallkunde, Garmisch-Partenkirchen, Germany, 1988

26 V. Koeninger and E. Fromm, 'Einflüsse von Alterung und Kontamination auf die Degradation von Gold-Aluminium-Ballbonds', (Influence of Ageing and Contamination on the Degradation of Gold-Aluminum Ball Bonds), Verbindungstechnik in der Elekronik und Feinwerktechnik, Düsseldorf, DVS-Verlag, 1996, 8 (4), 193

27 E.M. Philofsky, Solid-State Flectronics, 1970, 13, 1391

28 G. Majni and G. Ottaviani, J. Crystal Growth, 1979, 47, 583

29 P.K. Footner, B.P. Richards and R.B. Yates, Quality and Reliability Engineering International, 1987,3, 177

30 MIL-STD-883E

31 A. Russell, K Xu, S. Chumbley, J. Parks and J. Harringa, Gold Bull, 1998, 31, (3), 88

32 M. Judge, New Scientist, 1997, March 8th, pp 37

33 M. Poniatowski and M. Clasing, Gold Bull., 1972, 5 (2), 34

34 C.W. Corti, Gold Bull, 1999, 32 (2), 39 